\title{
BMJ Open Challenges in the implementation of primary health care reforms: a qualitative analysis of stakeholders' views in Turkey
}

Ana Belén Espinosa-González, ${ }^{01}$ Charles Normand ${ }^{2,3}$

To cite: Espinosa-González AB, Normand $\mathrm{C}$. Challenges in the implementation of primary health care reforms: a qualitative analysis of stakeholders' views in Turkey. BMJ Open 2019;9:e027492. doi:10.1136/ bmjopen-2018-027492

- Prepublication history and additional material for this paper are available online. To view these files, please visit the journal online (http://dx.doi. org/10.1136/bmjopen-2018027492).

Received 27 0ctober 2018

Revised 9 May 2019

Accepted 1 July 2019

A Check for updates

(c) Author(s) (or their employer(s)) 2019. Re-use permitted under CC BY-NC. No commercial re-use. See rights and permissions. Published by BMJ.

${ }^{1}$ Centre for Health Policy, Institute of Global Health Innovation, Imperial College London, London, UK

${ }^{2}$ Professor of the Economics of Palliative Care and

Rehabilitation, Cicely Saunders Institute, King's College London, London, UK

${ }^{3}$ Centre for Health Policy and Management, Trinity College, University of Dublin, Dublin, Ireland

\section{Correspondence to} Ana Belén Espinosa-González; a.espinosa-gonzalez15@ imperial.ac.uk

\section{ABSTRACT}

Objectives This study aims to assess the implementation of the Family Medicine Programme (FMP), which has taken place in Turkey from 2005 to 2010 as a set of comprehensive primary health care $(\mathrm{PHC})$ reforms and involved changes in professional organisation (eg, family medicine specialisation) and service provision (eg, patients' registration list). Our particular interest is to identify the challenges and limitations that PHC physicians and academicians have encountered in the implementation of the FMP which could have influenced the delivery of care and utilisation of services.

Design We applied the framework method to analyse data obtained through semi-structured interviews conducted in the field. This qualitative approach involved the categorisation of raw data into a predefined framework, which comprised challenges and limitations identified in the literature, and the emergence of a new framework, whose categories corresponded to challenges and limitations identified through thematic analysis of our data. Setting PHC centres and academic departments from five Turkish provinces

Participants PHC physicians and academicians involved in training and/or research were invited to participate. 20 participants agreed to take part and, due to schedule limitations, 15 participants (seven PHC physicians and eight academicians) completed the interviews.

Results Shortcomings in the planning of the reforms, inadequate commitment to integration of PHC in the system and collateral effects of a market model in healthcare emerged as limitations to successful FMP implementation. Uncertainty about care quality and physicians' ethical values as well as perceptions of organisational injustice among healthcare workers were contributing challenges.

Conclusions A systems thinking approach in the FMP design and implementation could help foresee and address these limitations. In decentralisation processes, such as FMP, shared governance by including PHC stakeholders in policy-making and planning could alleviate misalignment of interests and positively affect PHC performance, for example, by removing barriers to gatekeeping implementation.

\section{INTRODUCTION}

In 2018, international health stakeholders representatives met in Astana, Kazakhstan, to commemorate the 40th anniversary of the

\section{Strengths and limitations of this study}

- The study uses primary data obtained through semi-structured interviews with family physicians and primary health care (PHC) academicians in Turkey 5 years after the reforms reached country-wide implementation.

- The steps of the framework method, such as classification of raw data against a predefined theoretical framework and reiteration of backward and forward analytical process with the code index, enhance the transparency of analysis and credibility of results.

- The triangulation of themes obtained from PHC academicians' interviews, physicians' interviews and literature increases the trustworthiness of the findings.

- A pilot interview in the field, which would have improved the wording of questions, was not possible due to time limitations.

- Participant sampling mechanism (ie, purposeful and snowball sampling) may lead to (self-) selection bias and the use of interpreter may lead to omission of information due to interpreter-participant shared assumptions.

Declaration of Alma-Ata ${ }^{1}$ and renew their commitment to pursue the implementation of primary health care (PHC) as the means to achieve Universal Health Coverage. ${ }^{2}$ Due to its characteristics of accessibility, coordination, comprehensiveness and continuity, ${ }^{3}$ PHC meets the ideal conditions to serve as the first and main point of contact with the health system and provide preventive, curative and palliative healthcare for individuals and their communities. ${ }^{4}$

Since the Declaration of Alma-Ata, reforms in PHC have been marked by international economic and political events, including global economic crises and the fall of the Soviet Union, which left many countries in transition in an environment of neo-liberal and market-oriented reforms. ${ }^{5}$ These reforms were economically and logistically supported 
by the World Bank, global health leader at that time, ${ }^{6}$ and particularly involved the decentralisation of health services, including the strengthening of PHC through the implementation of the family medicine (FM) model. ${ }^{7}$ Among the policy recommendations was the implementation of compulsory FM training for PHC physicians, which was also imposed by European Union (EU) law on EU member and candidate countries, including Turkey. ${ }^{8-10}$

Although not a transition country, the health system in Turkey also underwent in-depth health reforms, particularly in the preparations for the official EU accession negotiations, which started in $2005 .^{11-13}$ In 2003, the government implemented a health reform package, known as the Health Transformation Programme (HTP), which was supported by the World Bank and included reforms in financing (eg, unification of the different types of health insurance), delivery (eg, strengthening PHC) and governance (eg, increasing hospitals' autonomy as well as decentralisation of management from ministry to regions)..$^{114-16}$

In this study, we focus on the PHC reforms, known as the Family Medicine Programme (FMP), which were first piloted in the central-northern city of Düzce in 2004 and extended in a phased manner until reaching country-wide implementation in $2010 .{ }^{17} 18$ This programme contained a very comprehensive set of reforms. Before the programme, PHC centres were owned by the state and distributed mostly in rural and remote areas. ${ }^{19}$ Physicians working in those centres were public employees paid on salary basis without postgraduate training. Although FM had been a medical specialty in Turkey since 1982, ${ }^{20}$ postgraduate training was not compulsory to work in PHC. ${ }^{21}$ Moreover, the lack of properly organised PHC centres and education in the medical schools contributed to the low popularity of FM training among medical students. ${ }^{172}$ The existing FM specialists occupied posts in emergency departments at hospitals and other services. ${ }^{23}$ The FMP aimed at strengthening PHC by (1) transferring the ownership of facilities to healthcare providers, (2) placing family physicians (FPs) in charge of FM units, which consisted of an FP and a nurse servicing an average of 3000 patients, (3) implementing capitation-based payments with performance-based supplements by which FPs were assigned a payment that decreased if they failed to achieve performance requirements, and (4) developing electronic medical records, which were used to monitor performance-based indicators. ${ }^{1724}$

Evaluations of the healthcare access and outcomes after the reforms have been generally positive, with an improvement in children vaccination and antenatal care, ${ }^{1625}$ as well as an increase in patient satisfaction. ${ }^{26}{ }^{27}$ However, other studies reported a decrease in healthcare quality in the context of payments for performance, which perversely led FPs to prioritise the development and recording of activities for which performance was measured, such as vaccinations, at a cost of neglecting unmonitored areas of care, such as blood pressure measurement. ${ }^{28-30}$ In addition, evaluations of the implementation of FMP pointed out some problems. First, FPs working in the service lacked experience in PHC. ${ }^{31} 32$ After the implementation of the FMP, the FM specialists working at the hospitals were invited to join the FMP. However, due to the lack of specialised FPs, a short adaptation training was designed to allow practitioners and specialist physicians from other branches to quickly obtain licences to work as FPs in PHC. ${ }^{23} 33$ Therefore, two types of PHC physicians, those with FM specialisation and those without, were working in the PHC service under the same contract and work conditions.

Second, the lack of specialised health workers, diagnosis and treatment resources caused the population to bypass PHC and attend directly secondary and tertiary services, which was possible because a referral system was not implemented.$^{34}$ Compulsory gatekeeping was piloted in 2006 but it failed due to FPs' high workload and resistance from population and hospital physicians. ${ }^{33} 35$ However, the use of PHC was incentivised by including co-payment in secondary and tertiary care. ${ }^{17}$

Third, although the programme had the support of the actors in the health administration, ${ }^{36}$ it met resistance from the medical associations, physicians and the general public, who saw this transformation as a neoliberalist strategy following the same trends of the decentralisation and privatisation as other public services. ${ }^{37} 38$ This opposition pointed out that the stakeholders were not sufficiently taken into account in the design and the implementation of the FMP. ${ }^{24}$ As supported by systems thinking approaches, the inclusion of stakeholders in the design of healthcare reforms is a valuable resource to anticipate potential undesirable effects of the interventions which may have otherwise remained unidentified until reforms are evaluated. ${ }^{39}{ }^{40}$ There was still room for strengthening PHC after the implementation of the reforms in Turkey ${ }^{41}$ and a systemic analysis gathering some of the stakeholders perspectives could inform key aspects for the improvement. ${ }^{42} 43$ This study builds on the previous body of research with the aim to assess the challenges and difficulties that FPs and academicians involved in FM training had encountered in the implementation of the FMP which could have influenced the delivery of care and utilisation of services.

\section{METHODS}

We designed a qualitative study supported by modified or Straussian grounded theory, which accepts the possibility of researcher's preconceptions and the application of a framework for the analysis. ${ }^{44}$ The approach is deductive-inductive, since it builds up from a predefined analytic framework, which is based on the limitations in the FMP implementation identified in the literature, but uses induction and interpretation in the development of the themes, which are the final outputs of the analysis. 
RESEARCH QUESTIONS

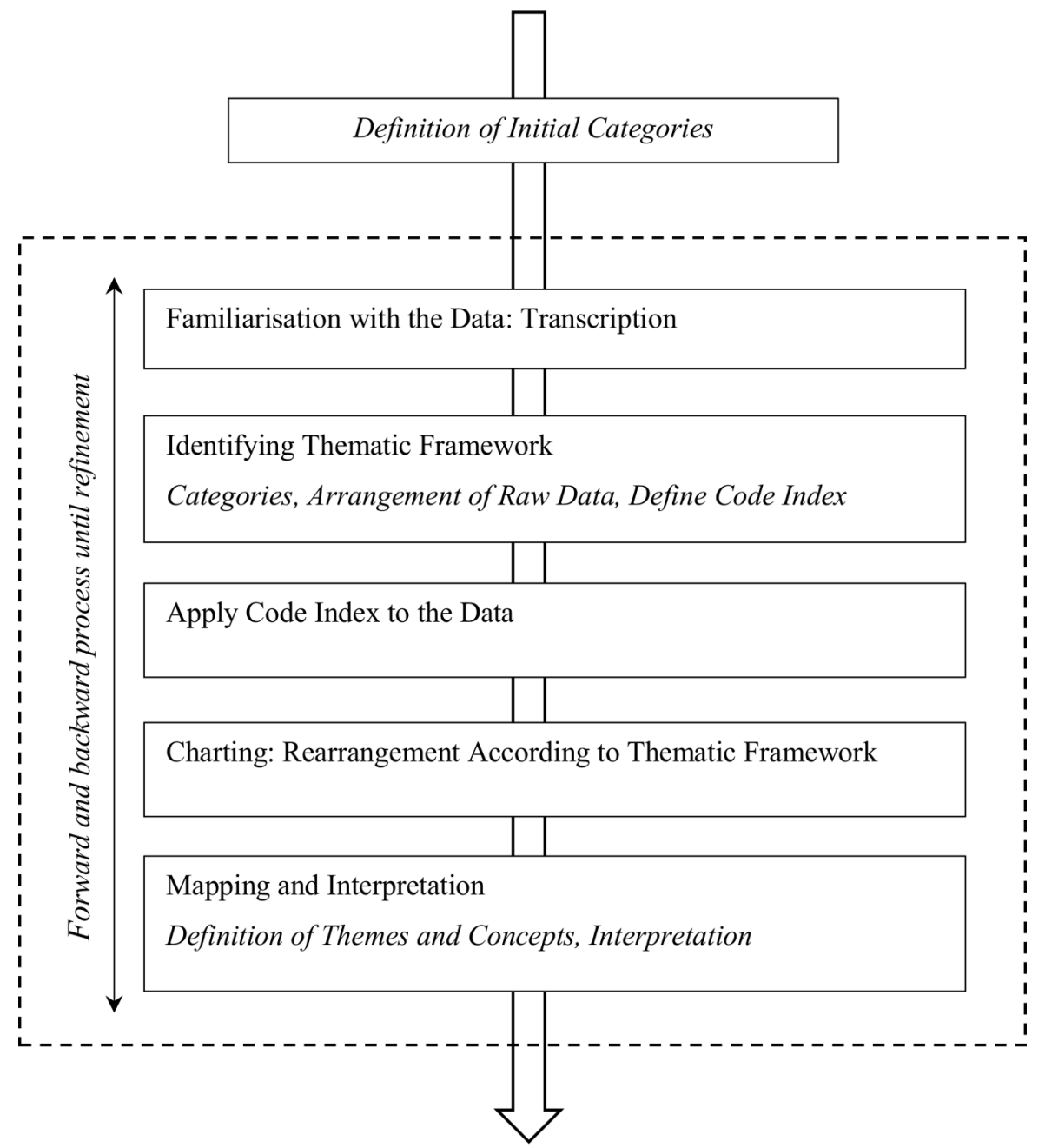

RESEARCH QUESTIONS ANSWERED

Figure 1 Steps in framework method analysis.

\section{Analysis}

For the management of the data and generation of themes, we followed the framework method, which was developed by the National Centre for Social Research in the $\mathrm{UK}^{45}$ and is widely used in health policy and health services research. ${ }^{46}$

This method applies several steps in the analysis of the data (figure 1): (1) familiarisation with the data by transcribing the audio-recorded interviews, (2) identification of initial categories by applying the initial thematic framework to classify the chunks of raw data and use of in vivo and axial coding to group the information into refined codes traceable with a numeric code index, (3) restructuring the analytic framework by grouping the refined codes into indexed refined categories, which are then abstracted into initial themes and combined into final themes afterwards, and (4) mapping the themes against the raw data followed by their interpretation and discussion. ${ }^{45}$ The first author conducted the analysis of data. Major or dominant themes were abstractions that accounted for frequent codes and categories that arose in the interviews. Minor themes were abstractions that accounted for codes and categories that emerged from interviews but were related to or supported a dominant theme. ${ }^{4748}$ Online supplementary materials illustrate the process of coding from chunks of raw data, categorisation and abstraction of final themes that was followed in the analysis our data.

\section{Data collection and sampling}

The data were obtained through semi-structured interviews conducted in Turkey in May 2015 (5years after the programme reached country-wide implementation). Interviews were conducted by the first author, who is also an FP involved in research. The interviews with FPs took place in the health centres and those with academicians took place in university departments. The interview questions were framed around the initial challenges identified in the literature, which corresponded to the following initial categories: (1) education and training of FPs, 


\begin{tabular}{ll} 
Table 1 & Semi-structured interview schedule \\
\hline 1 & $\begin{array}{l}\text { What are the main subjects in the FPs' adaptation } \\
\text { programme / FM specialisation programme? }\end{array}$ \\
2 & $\begin{array}{l}\text { Have the skills and clinical practice improved after } \\
\text { this adaptation programme? }\end{array}$ \\
3 & $\begin{array}{l}\text { What are the main contributions to FPs' high } \\
\text { workload? }\end{array}$ \\
4 & $\begin{array}{l}\text { What do you think about the referral system? What } \\
\text { are the limitations for its implementation? }\end{array}$ \\
5 & $\begin{array}{l}\text { What are the population's attitudes towards the PHC } \\
\text { service after FMP? }\end{array}$ \\
6 & $\begin{array}{l}\text { What are the most positive points of the FMP (for FPs } \\
\text { and population)? }\end{array}$ \\
7 & $\begin{array}{l}\text { What are the most negative points of the FMP (for } \\
\text { FPs and population)? }\end{array}$ \\
8 & $\begin{array}{l}\text { What interventions would you have implemented in } \\
\text { order to improve PHC in Turkey? }\end{array}$ \\
\hline
\end{tabular}

FMP, Family Medicine Programme; FP, family physician; PHC, primary health care.

(2) PHC delivery process and (3) population attitudes. Additionally, we included broader categories,such as best points, worst points and suggestions for improvements, to facilitate the emergence of unforeseen information and add more inductive weight to the study. Table 1 shows the interview schedule, which was discussed between both authors prior to the interviews.

Participants were (1) FM academicians working in medical university departments and (2) FPs (with or without specialisation) working in the FM centres. We used purposeful and snowball sampling. The academicians were identified from relevant publications. The FPs were contacted through the Turkish Medical Association and snowball sampling. The participants were contacted by email, sent the participant's information leaflet with information about the researchers, research aims, the methodology and the strategies taken to ensure the anonymity of their data. The research instruments (eg, informed consent form, study information leaflet, scheme of interview questions) were provided in English and Turkish languages. Participants could also choose to be interviewed in English or Turkish according to their preference. Participants were sent the interview questions at least 2 weeks before the scheduled interview. When the participant requested, a Turkish interpreter assisted with the interview process following a three-way inquiry process $^{49}$ in which the researcher asked the question in English, the interpreter translated into Turkish and the participant answered in Turkish. Then the interpreter translated the answer into English. The interpreter was previously instructed on the research topic and signed a confidentiality agreement. ${ }^{50}$ All interviews were audio-recoded and lasted around $60 \mathrm{~min}$ and field notes were taken after the interviews. Participants were not known to the interviewer or interpreter.

\section{Patient and public involvement}

No patients were involved in the design, analysis or reporting of this study.

\section{Validity}

The framework method is designed to enhance the validity of the results and the rigour and transparency of the analysis. Prior to the analysis, the individual transcripts were sent to each participant to check their trustworthiness. During the analysis, the codes defined were identified with code indices, which help the researcher and evaluator to follow the analytical process and to identify participants' quotes that illustrate the themes. The codes and themes were related to the research questions during the process in order to eliminate irrelevant data. This forward and backward analytical process was followed several times to check for over-interpretation or researcher inference bias during codifying and theme definition. Triangulation was done between the academician and FP groups to confirm the common themes. ${ }^{51}$ The literature was checked for confirming and disconfirming evidence, as this enhances the validity of the study providing credibility for the information. ${ }^{52} \mathrm{~A}$ reflection on the themes is performed to assess for credibility of the inferences and the accuracy according to the transcripts. ${ }^{52}$

\section{RESULTS}

Participation was $75 \%$ of those that initially consented, leaving 15 out of 20 participants (table 2).

The main reason for withdrawing was schedule incompatibility. Participants were from five provinces: Ankara, Eskişehir, İzmir, Adana and İstanbul. The average age of the participants was 48 (ranged between 42 and 57), the average years of experience in their field was 22 (ranged between 13 and 30 ) and $73 \%$ of participants were female. Seven participants were FPs, of which two were FM specialists. The remaining eight participants were academicians working in university departments, had FM specialisation training and were FM trainers either in the specialisation degree or in the adaptation programme for FPs after the FMP. As explained in the Methods section, the interview questions were framed around a predefined framework consisting of initial categories of limitations for the implementation of the FMP reported in the literature. The saturation point was reached following the twelfth interview, after which no new themes emerged from either academician or FP interviews. ${ }^{53}$ The final framework had three dominant themes or sources of barriers in the implementation of the FMP and three minor themes that, as reported, contributed to the difficulties encountered (figure 2).

\section{Dominant themes}

Planning of FMP implementation

This dominant theme was constantly present in the interviews and emerged from the grouping of the following initial themes: (1) insufficient anticipation on the capacity 
Table 2 Participants' demographic information

needed, in both infrastructure and workforce, to implement the programme, which was reported to affect the training and competences of FPs as well as increase workforce shortages and FPs' workload and (2) lack of population awareness of the changes in the PHC service.

Both of these were reported to contribute to increased secondary and tertiary care utilisation: "Majority of Turkish population do not know about PHC. They don't know, directly they go to secondary care, because they are not knowledgeable of this.' (participant 5)

A participant disconfirmed that the workload had increased (due to FPs shortages): 'They say they are working so hard, they have hundreds of patients a day, but we have researched with them and the average patients is 30 a day.' (participant 6) (disconfirming evidence)

\section{Political commitment to FM integration}

This was also a dominant theme, highlighted in three main aspects: (1) there was a lack of political commitment to FPs' training or implementing compulsory FM specialisation, (2) participants stated that the referral system was not implemented for political reasons, as it might have caused a political backlash from patients who do not want to be constrained and doctors who fear a loss of income ('The government has very good (public) support because of the HTP implementation and they don't want to lose it, so they don't want to introduce the referral system' (participant 8)), and (3) there was insufficient FM stakeholder involvement in the health policy-making process.

\section{Market healthcare model}

This third dominant theme resulted from: (1) perceived consequence of the monitoring of performance-based indicators and facilities' ownership in causing high FPs' workload, (2) performance-based payments that put emphasis on the quantity of healthcare instead of quality and may discourage other activities and disease monitoring, and (3) an increase in consumption of health services by the population.

There were some positive comments as well: (1) there was an increase in patient satisfaction (because of increased accessibility and continuity) ('People are very happy not having referral chain in Turkey, satisfaction is high and they have freedom to go everywhere' (participant 10)) and (2) the implementation of FM discipline had positive consequences for the workforce and population ("A lot of students started to say: I want to be a PHC physician, they have an academic road they can go, this is a very important thing for improving themselves' (participant 6)).

\section{Minor themes}

Uncertainty about quality

This minor theme emerged from: (1) training of FPs to work in PHC was insufficient since the adaptation training was short and their workload limited their time for competence development; moreover, some FPs who joined the FMP came from other branches and lacked FM and PHC experience and (2) performance-based indicators only concerned the quantity of care provided but the quality was not measured. 


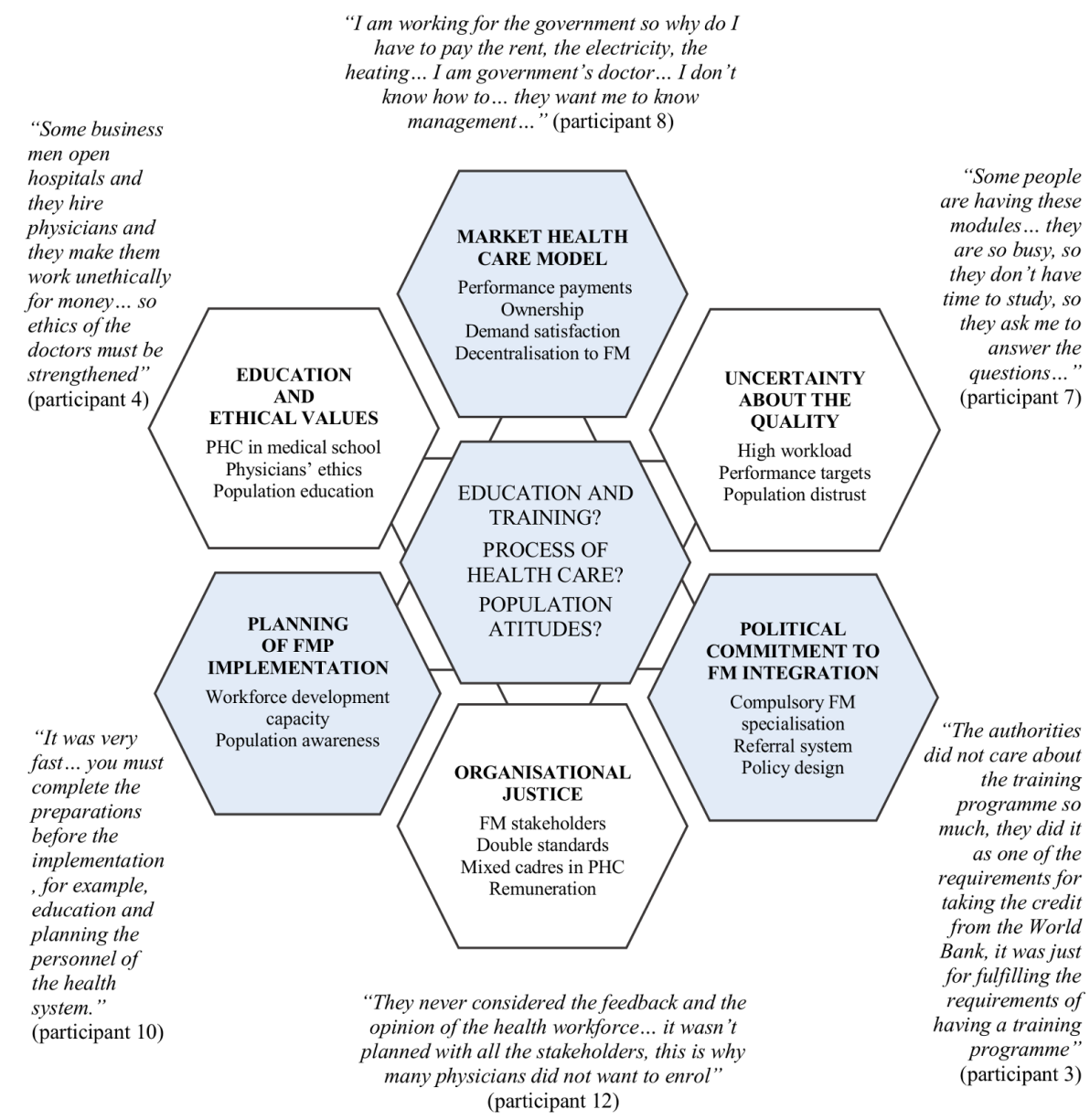

Figure 2 Themes emerged in the analysis. In the centre of the figure, the initial categories, which constitute the initial framework based on the literature, surrounded by the dominant and minor themes as described in the main text. FM, family medicine; PHC, primary health care.

Participants reported that the quality of training and healthcare in PHC can impact population trust in FPs, for example, 'The education of family physicians is very important; people must trust family physicians, you can't say 'trust him', people must learn that physicians have knowledge.' (participant 11)

A participant disconfirmed that doctors who entered in the FMP through short adaptation training lacked experience: 'Doctors working in the PHC (before the programme) without specialisation were very experienced doctors, but they have no vocational training in family medicine.' (participant 10) (disconfirming evidence)

Moreover, another participant stated that population trust for the service was increasing: 'They (patients) believe us, more than (the) hospital, after going to the hospital they come here to ask us, they trust us more.' (participant 2) (disconfirming evidence)

\section{Organisational justice}

This minor theme emerged from: (1) decreased physicians motivation due to lack of inclusion of FM stakeholders in the FMP design and implementation and lack of support from public authorities for doctors' rights, (2) tensions and discomfort in the work environment due to double education standards (FM with and without specialisation), ambiguity of job description and negative performance-based payment cuts with peer supervision, and (3) lack of respect and violence from patients towards doctors (this subject was brought up in all interviews with FPs and most of the academician interviews): 'There was a spiritual relationship between the patient and the doctor in Turkey, people had an undefined respect for the physicians, but this is gone, that's what we objected to the most.' (participant 4)

However, a participant added that: 'FM specialists working in PHC are happy, because they get more salary than other doctors. They also have a discipline. Before this implementation, they were only doctors, now they are specialists in the country. Now they are the members of the FM system, I think this is important.' (participant 10) (disconfirming evidence)

\section{Education and ethical values}

The last minor theme emerged from: (1) need for strengthening the FM education in medical school as an essential step to strengthen PHC ('PHC needs to be strengthened, that goes for all (doctors), every physician must be prepared to become an FP. For example, in (the) third year of education, students start saying 'I want to be gynaecologist', 'I want to be an internist', no, you first 
must want to be an FP' (participant 4)), (2) importance of strengthening doctors' ethical values in market model health systems, and (3) importance of enhancing population awareness on health issues and services in order to control the misuse of health services ('Population is very demanding because family physicians that are working at PHC centres don't have time to educate them' (participant 7)).

Therefore, the absence of proper and timely preparations for FMP implementation (ie, FPs training infrastructure and population campaigns on improvements in PHC service), the reported insufficient political commitment to the integration of FM (ie, lack of compulsory FM specialisation and gatekeeping mechanism), and problems related to market model (ie, increase in workload due to managerial tasks and performance indicators and increase in patients' demands) were the dominant themes that affected the competence of FM, the process of healthcare delivery and population attitudes towards PHC. Uncertainty about quality (ie, lack of training and quantitative performance indicators) and organisational injustice (ie, negative performance-related payments and duality in physicians' training and PHC professional cadre) were also undermining the progress of FMP. In addition, weak population awareness and doctors' ethical values hindered the path towards the proper integration of FM and PHC.

\section{DISCUSSION}

The FMP was implemented in a relatively short period of time, and this could explain the lack of preparedness or insufficient planning encountered in its implementation. ${ }^{54}$ In a period of just 5 years (from 2005 to 2010), the PHC workforce in Turkey went from being unqualified public employees working in community-based health centres status to being specialised contract-based FPs in charge of assigned patient lists, health facility management and being assessed against performance requirements, without adequate training. What has been otherwise reported as a successful reform could have benefited from some additional interventions. ${ }^{55}$

In general, as noted in the introduction, the inclusion of FM stakeholders in the health policy-making process, in particular, in those concerning PHC (eg, by involving FPs in the design and implementation of the adaptation training programme or design of payment mechanisms), would have facilitated the integration of FM into the health system, particularly in the context of developing a decentralised PHC service that puts the FPs at the front line.$^{56}$ In decentralised and multiple stakeholders' health systems, the inclusion of stakeholders in policy and decision-making process fuels the common sense of belonging to the same system and promotes the pursuit of shared goals. ${ }^{57}$

As mentioned in the introduction, there is evidence that supports the application of systems thinking approaches in the design and evaluation of healthcare reforms ${ }^{58-60}$ Systems thinking considers the dynamics and synergies between different health system stakeholders and functions ${ }^{60}$ when analysing health system performance. It can explain, for example, how interventions applied at tertiary care level (eg, fee-for-service payments for hospital providers) can contribute to, for example, resistance to gatekeeping implementation, or how inadequate FPs training and PHC education in medical schools may influence population trust and acceptance of the service.

A systems thinking analysis of the reform ahead of implementation could help anticipate the workforce and infrastructure required for the programme, leading to an increase in PHC education in medical schools and capacity for FM specialisation training. Although an adaptation programme was certainly necessary to allow the integration in the FMP of physicians already working in the field, this should not be offered as an alternative to FM specialisation to newly graduated medical students. However, due to the workforce shortage and lack of adequate training infrastructure, this was still offered 5 years after the implementation of the programme. Compulsory FM specialisation (which is an EU regulation for all member and candidate countries and also a World Bank policy consideration for the HTP loan) had not yet been implemented neither were there arrangements in place for it. ${ }^{21}$ This duality in education and in the professional cadre, as well as high workload resulting from inadequate management skills required in the new market model PHC service, affected the work environment and impacted job satisfaction and motivation. ${ }^{2124}$

Physician workload was another reported barrier to gatekeeping implementation. ${ }^{34} \mathrm{~A}$ systems thinking approach in policy design and implementation could have helped anticipate the capacity required to implement a referral system. Alignment of interests (and payment mechanisms) between hospital and PHC physicians could alleviate the barriers to implementation of gatekeeping reported by participants. ${ }^{55}$ Moreover, raising population awareness about PHC and FPs' skills as well as about the benefits of dealing with health problems in the community, where health promotion and prevention can be also delivered, would contribute to improving population attitudes and trust in $\mathrm{PHC}^{1724}$ and could also decrease barriers to gatekeeping implementation. This in turn would improve coordination of health services and prepare the field for better prevention and management of chronic conditions. ${ }^{29}$ In the interviews, concerns were raised about the quality and overproduction of healthcare, attributed to quantitative performance indicators and incentives to consume health services. A review of indicators and payment mechanisms as well as the strengthening of doctors' ethical commitments to provide appropriate healthcare could address these concerns. ${ }^{17}$ 
Political will to implement the programme was considered crucial. ${ }^{16} 55$ However, the reasons behind this political will could have also prevented its full implementation. There are three possible rationales behind the implementation of FMP, which accompanied broader decentralisation interventions as described in the HTP package: ${ }^{14}$ (1) legitimisation, that is, the inclusion of PHC stakeholders represents the trust the government puts in them to legitimately take part in the health system recognising the benefits of PHC for population health; (2) self-interest, that is, motivation to achieve specific objectives and seek alignment of objectives with the stakeholders involved, and (3) performance, that is, seeking an increase in health systems efficiency and improved outcomes. ${ }^{61}$ In our study, the lack of inclusion of stakeholders in FMP design and implementation undermined perceptions of organisational justice within the PHC professional cadre, suggesting that the first rationale might not have been behind it. Literature describes an improvement of reported performance-related outputs. ${ }^{55}$ There are questions about the extent of improvements in efficiency, ${ }^{29}$ and the lack of gatekeeping may have hindered gains in efficiency. Political self-interests could have been the rationale behind these reforms. The FMP reached country-wide implementation in 2010, thanks to political commitment, and was an important element in the campaign for the upcoming 2011 general elections. ${ }^{16}$ However, fear of losing votes due to hospital stakeholders and population discontent with some interventions, such as gatekeeping, could have prevented public authorities from full implementation of FMP ahead the elections. Following this, the government's agenda (and interests) may have shifted towards the enhancement of secondary and tertiary care (eg, establishment of the Law on Hospital Autonomy). ${ }^{16}$

As positive points, FM acquired public recognition as a scientific discipline and this enhanced motivation in the sector as well as attracting the interest of medical students. ${ }^{17}$ Moreover, there was an increase in continuity and accessibility of healthcare ${ }^{33}$ and studies reported improvement in population health status as well as satisfaction with the service. ${ }^{16}$

In 2007/2008, the WHO Primary Care Evaluation Tool was applied to assess the FMP implementation in Bolu and Eskişehir. ${ }^{24}$ The results of our analysis 7 years later confirmed those reported in their study and additional literature. Figure 3 illustrates a summary of the observations stated above framed on the Primary Health Care Activity Monitor for Europe (PHAMEU) framework, ${ }^{62}$ based on the Donabedian structure-process-outcome mode $^{63}$ and Starfield's PHC core attributes of comprehensiveness, accessibility, continuity and coordination. ${ }^{3}$ As shown in figure 3, strengthening of governance, by including FM stakeholders in the policy-making process and increasing population awareness of PHC, could have a positive cascade effect on the rest of the functions, such as payment alignment, FM training and population attitudes. This would favour physicians' competences and self-confidence, which could improve workload, motivation and increase population trust. Those conditions could facilitate the implementation of a referral system, improve the comprehensiveness of the service and appropriate access.

\section{Strengths and limitations}

In contrast with our deductive-inductive approach, there are advantages in analysing health service reforms from a more inductive perspective, such as case studies or historiography, which can produce explanations and generalisations of the results. ${ }^{44}$ However, inductive inference requires realisation of the same study several times to obtain empirical confirmation of the veracity. A strength of the approach taken in this study is that the framework method is systematic and the process of the data analysis can be tracked. The methods used to give validity to the analysis have been described previously. The sample was heterogeneous, including participants from different provinces and different professional profiles (eg, academicians and FPs with and without specialisation), which adds credibility and reliability to the results. Purposeful and snowball sampling methods are useful when the goal is to obtain opinions of informed participants. However, these sampling mechanisms, as well as the fact that five participants withdrew from the study before conducting the interviews, may have introduced self-selection bias, particularly when assessing health policy. ${ }^{64}$ The contrasting of themes between academicians' and physicians' groups, the reporting of disconfirming evidence and the triangulation of themes with literature were intended to address this. Another limitation in the data collection was the lack of a pilot interview, which would have improved the wording of questions but was not possible due to lack of time. Similarly, seeking participants' validation of the results and triangulation of the themes with a research group could have added validity. The use of interpreter in cross-language interviews can increase the trust and comfort of participants during the interview process but may lead to omission of information due to interpreter-participant shared assumptions. To address this, the first author was leading all interviews and had the opportunity to seek clarification or additional information. The interpreter was instructed on the purpose of the study and the type of information sought with each question. ${ }^{50}$ Finally, the first author had the same professional background (ie, FPs involved in PHC research) as the participants. This was positive for the recruitment process but excessive empathy between the interviewer and interviewee can lead to 'shared conceptual blindness' ${ }^{65}$ Our first step to mitigate researcher bias was recognising the potential for such bias in all stages of the process. This was the main reason to apply the framework method, since it is systematic and consists of specific steps that allow tracking the data and checking their reliability throughout the process. Further measures to reduce researcher bias were the application of an initial framework based on the literature to identify the themes 


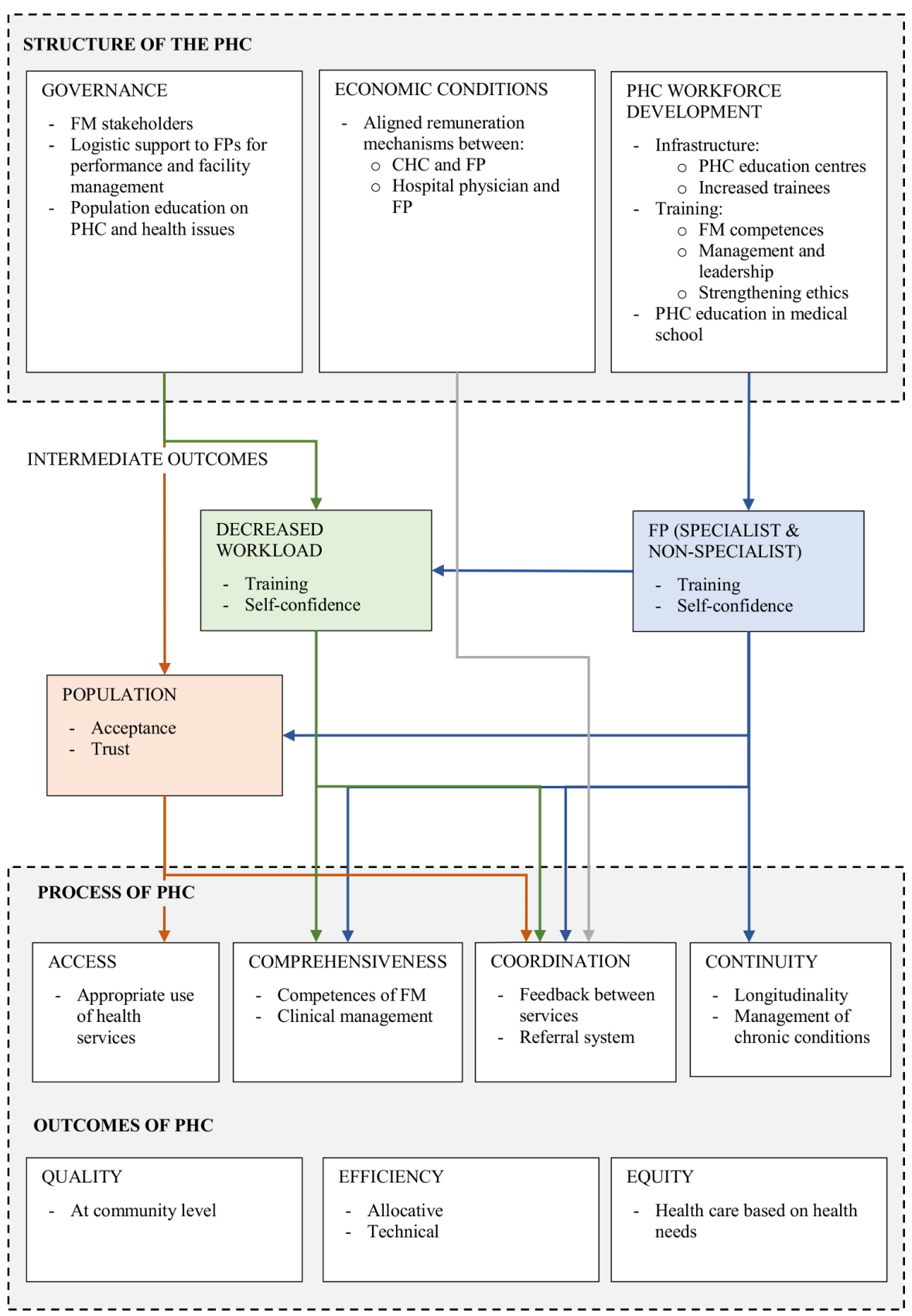

Figure 3 Policy observations framed in the PHAMEU framework, ${ }^{62}$ based on the Donabedian model to measure healthcare quality. ${ }^{63} \mathrm{CHC}$, community health centre; FM, family medicine; FP, family physician; PHC, primary health care.

and the use of a semi-structured interview schedule, which was discussed between both authors prior to the interviews. Additionally, participants received the questions before the interviews, which also limited to some extent the spontaneous inquiry.

\section{CONCLUSIONS}

Our study suggests that a lack of proper planning, insufficient political will to integrate FM (and PHC) in the system and problems related to marketisation of the health system are the sources of challenges in the FMP implementation. These were supported by organisational injustice perceptions in the PHC professional cadre and concerns about physicians' ethical values and care quality in market healthcare systems. A systems thinking approach, which takes into account the interactions between stakeholders and interventions when designing and evaluating reforms, could help foresee barriers in the health reforms implementation.

Political will for legitimate inclusion of PHC stakeholders in governance would positively impact the rest of the system. This can particularly improve, on the one hand, the barriers limiting the implementation of the referral system and, on the other hand, the infrastructural and technical capacity for PHC workforce development. This can have positive effects in the coordination 
and comprehensiveness of health services and prepare the field for better prevention and management of chronic conditions, which are worldwide health systems and population wellness threats. ${ }^{66}$

The evaluation of health sector reforms in a country such as Turkey has global health relevance since its results can guide health policy and decision makers in the design and implementation of similar reforms in other countries. ${ }^{67}$ The reforms should be adapted to each country context and governments should assess how these interventions are understood and accepted by the population and other stakeholders. It is important to understand how to introduce PHC reforms into health systems in low-income and middle-income countries since their proper implementation contributes to the strengthening of health systems, which would enhance capacity building for sustainable economic and social development. ${ }^{68-71}$

The implementation of $\mathrm{PHC}$ is a long process that requires strong commitment and determination. ${ }^{1}$ It is our belief that the benefits of the reforms in Turkey were just starting to be observed during the period of this study, with increasing public trust in the service and medical students' interests in working in PHC. The strengthening of PHC should be pursued whatever the difficulties. A solid base for the health system is crucial for health systems strengthening towards the achievement of universal health coverage. ${ }^{71}$

Acknowledgements The authors would like to thank the family physicians and family medicine academicians that took part in the study for their valuable time and contribution.

Contributors $A E G$ and $C N$ designed the study. AEG conducted the interviews and analysis and wrote the initial draft with inputs from CN. CN reviewed the final manuscript.

Funding The authors have not declared a specific grant for this research from any funding agency in the public, commercial or not-for-profit sectors.

Disclaimer The views expressed in the article are solely the responsibility of the authors and do not represent the positions of the institutions in which they work.

Competing interests None declared.

Patient consent for publication Not required.

Ethics approval The study was approved by the Health Policy \& Management / Centre for Global Health Research Ethics Committee in Trinity College Dublin (Application 15F/2015/02) and was assessed by the Research Ethics Committee in Ankara University, which did not require additional ethical approval for this study.

Provenance and peer review Not commissioned; externally peer reviewed.

Data sharing statement Analytical process and code index are provided in supplementary materials. No additional data are available.

Open access This is an open access article distributed in accordance with the Creative Commons Attribution Non Commercial (CC BY-NC 4.0) license, which permits others to distribute, remix, adapt, build upon this work non-commercially, and license their derivative works on different terms, provided the original work is properly cited, appropriate credit is given, any changes made indicated, and the use is non-commercial. See: http://creativecommons.org/licenses/by-nc/4.0/.

\section{REFERENCES}

1. WHO, UNICEF. Declaration of Alma-Ata. International Conference on Primary Health Care, Alma-Ata, USSR, 6-12 September 1978. Geneva and New York: World Health Organization, 1978.

2. WHO, UNICEF. Declaration of Astana. Global Conference on Primary Health Care: from Alma-Ata towards universal health coverage and the Sustainable Development Goals. Astana, Kazakhstan, Oct 2526, 2018. Geneva and New York, 2018. https://www.who.int/docs/ default-source/primary-health/declaration/gcphc-declaration.pdf. (accessed 13 Jan 2019).

3. Starfield B. Measuring the attainment of primary care. J Med Educ 1979;54:361-9.

4. Saltman R, Rico A, Boerma W. Primary care in the driver's seat? Maidenhead: Open University Press, 2006.

5. Cueto $M$. The origins of primary health care and selective primary health care. Am J Public Health 2004;94:1864-74.

6. Lidén J. The World Health Organization and Global Health Governance: post-1990. Public Health 2014:128:141-7.

7. World Bank. World Development Report 1993: Investing in Health. New York: Oxford University Press, 1993.

8. Atun R. What are the advantages and disadvantages of restructuring a health care system to be more focused on primary care services? Copenhagen: WHO Regional Office for Europe, 2004.

9. Hansen J, Groenewegen PP, Boerma WGW, et al. Living In A Country With A Strong Primary Care System Is Beneficial To People With Chronic Conditions. Health Aff 2015;34:1531-7.

10. Starfield B. Primary care: an increasingly important contributor to effectiveness, equity, and efficiency of health services. SESPAS report 2012. Gac Sanit 2012;26 Suppl 1:20-6.

11. NÖ B. The health system, health policies and health transformation program in Turkey. Med Law 2009;28:23-45.

12. Kisa A, Younis MZ, Kisa S. A comparative analysis of the European Union's and Turkey's health status: how health-care services might affect Turkey's accession to the EU. Public Health Rep 2007;122:693-701-701 https://www.ncbi.nlm.nih.gov/pmc/articles/ PMC1936955/pdf/phr122000693a.pdf

13. Yıldırım HH, Hughes D, Yıldırım T. Markets, modernisation and national interest: three faces of patient choice policy in Turkey. Health Soc Care Community 2011;19:168-77.

14. World Bank. Turkey - Reforming the health sector for improved access and efficiency (Vol. 2) (English. Washington, DC, 2003. http:// documents.worldbank.org/curated/en/790111468779115222/ Turkey-Reforming-the-health-sector-for-improved-access-andefficiency

15. Menon R, Mollahaliloglu S, Postolovska I. Toward universal coverage: Turkey's green card program for the poor. Washington, DC, 2013.

16. Atun R, Aydın S, Chakraborty S, et al. Universal health coverage in Turkey: enhancement of equity. Lancet 2013;382:65-99.

17. Günes ED, Yaman H. Transition to family practice in Turkey. $J$ Contin Educ Health Prof 2008;28.

18. Mollahaliloglu S. The effect of human resources on health reforms: a Turkey case study: Boston, MA, 2008.

19. Ersoy F, Sarp N. Restructuring the primary health care services and changing profile of family physicians in Turkey. Fam Pract 1998;15:576-8.

20. Bașak O, Güldal D. Twenty years of academic family medicine departments in Turkey: an overview on the developmental process. Turkish J Fam Pract 2014;18.

21. Göktaș O, Tekin O, Cebeci S. Psychosocial evaluation of physicians receiving adaptation training in family practice. Turkish J Med Sci 2011; $41: 743-53$

22. Tanriover $\mathrm{O}$, Hidiroglu $\mathrm{S}$, Akan $\mathrm{H}$, et al. A qualitative study on factors that influence Turkish medical students' decisions to become family physicians after the health transformation programme. N Am J Med Sci 2014;6:39-44.

23. Ozsahin AK. Family practice in Turkey. Glob Health Promot 2014;21:59-62.

24. Kringos DS, Boerma WG, Spaan E, et al. A snapshot of the organization and provision of primary care in Turkey. BMC Health Serv Res 2011;11:90.

25. Ökem ZG, Çakar M. What have health care reforms achieved in Turkey? An appraisal of the "Health Transformation Programme". Health Policy 2015;119:1153-63.

26. Hone T, Gurol-Urganci I, Millett C, et al. Effect of primary health care reforms in Turkey on health service utilization and user satisfaction. Health Policy Plan 2017;32:57-67.

27. Stokes J, Gurol-Urganci I, Hone T, et al. Effect of health system reforms in Turkey on user satisfaction. J Glob Health 2015;5:020403.

28. Akman M, Sakarya S, Sargın M, et al. Changes in primary care provision in Turkey: A comparison of 1993 and 2012. Health Policy 2017; $121: 197-$

29. Cevik C, Sozmen K, Kilic B. How primary care reforms influenced health indicators in Manisa district in Turkey: Lessons for general practitioners. Eur J Gen Pract 2018;24:74-83.

30. Kilic B, Kalaca S, Unal B, et al. Health policy analysis for prevention and control of cardiovascular diseases and diabetes mellitus in Turkey. Int J Public Health 2015;60 Suppl 1:47-53. 
31. Yaman $\mathrm{H}$, Ozen M. Satisfaction with family medicine training in Turkey: survey of residents. Croat Med J 2002;43:54-7.

32. Yaman H, Ungan M. Türkiye'de bir tıp disiplini olarak aile hekimliğinin gelisimi, 2010.

33. Öcek ZA, Çiçeklioğlu M, Yücel U, et al. Family medicine model in Turkey: a qualitative assessment from the perspectives of primary care workers. BMC Fam Pract 2014;15:38.

34. OECD. Recent health reforms in Turkey OECD and IBRD/The World Bank, 2008.

35. Savas BS, Ö K, RÖ S. Health Care Systems in Transition: Turkey. Copenhagen: European Observatory on Health Care Systems, 2002

36. Akinci F, Mollahaliloğlu S, Gürsöz H, et al. Assessment of the Turkish health care system reforms: a stakeholder analysis. Health Policy 2012;107:21-30.

37. Ö E, Yavuz Cl, İlhan B. Soru ve Yanıtlarla Sağlıkta Kamu Özel Ortaklığı (Questions and Answers on Public Private Partnerships in Health). Ankara 2012.

38. Aktan AO, Pala K, Ilhan B. Health-care reform in Turkey: far from perfect. The Lancet 2014;383:25-6.

39. Atun RA, Menabde N, Saluvere K, et al. Introducing a complex health innovation-Primary health care reforms in Estonia (multimethods evaluation). Health Policy 2006;79:79-91 http://ovidsp.ovid.com/ ovidweb.cgi?T=JS\&PAGE=reference \&D=med5\&NEWS=N\&AN= 16406131

40. Gilson L, Elloker S, Olckers P, et al. Advancing the application of systems thinking in health: South African examples of a leadership of sensemaking for primary health care. Health Res Policy Syst 2014;12:30.

41. Pelone F, Kringos DS, Spreeuwenberg P, et al. How to achieve optimal organization of primary care service delivery at system level: lessons from Europe. Int J Qual Health Care 2013;25:381-93.

42. Langlois EV, Becerril Montekio V, Young T, et al. Enhancing evidence informed policymaking in complex health systems: lessons from multi-site collaborative approaches. Health Res Policy Syst 2016;14:20

43. Sheikh K, George A, Gilson L. People-centred science: strengthening the practice of health policy and systems research. Health Res Policy Syst 2014;12:19.

44. Giacomini M. Theory matters in qualitative health research. In: Bourgeault I, Dingwall R, De Vries R, eds. The SAGE Handbook of Qualitative Methods in Heatlh Research. London: SAGE Publications, 2010:125-57

45. Gale NK, Heath G, Cameron E, et al. Using the framework method for the analysis of qualitative data in multi-disciplinary health research. BMC Med Res Methodol 2013;13:117.

46. Pope C, Ziebland S, Mays N, et al. In: Pope C, Mays N, eds. Qualitative Research in Health Care: Blackwell Publishing, 2006:66-81.

47. Vaismoradi $\mathrm{M}$, Jones $\mathrm{J}$, Turunen $\mathrm{H}$, et al. Theme development in qualitative content analysis and thematic analysis. J Nurs Educ Pract 2016;6.

48. Ryan GW, Bernard HR. Techniques to Identify Themes. Field methods 2003;15:85-109.

49. Murray CD, Wynne J. Researching community, work and family with an interpreter. Community Work Fam 2001;4:157-71.
50. Williamson DL, Choi J, Charchuk M, et al. Interpreter-facilitated cross-language interviews: a research note. Qualitative Research 2011;11:381-94.

51. Mays N, Pope C. Quality in qualitative research. In: Pope C, Mays N, eds. Qualitative Research in Health Care: Blackwell Publishing, 2006:82-98.

52. Creswell JW, Miller DL. Determining Validity in Qualitative Inquiry. Theory Pract 2000;39:124-30.

53. Bowen GA. Naturalistic inquiry and the saturation concept: a research note. Qualitative Research 2008;8:137-52.

54. Günvar T, Kartal M, Toksun A, et al. The influence of health care reforms on work-related attitudes and anxieties of primary care physicians. Medicina 2011;47:90-8.

55. WHO. Successful health system reforms: the case of Turkey. Copenhagen, 2012.

56. Saraceno B, van Ommeren M, Batniji R, et al. Barriers to improvement of mental health services in low-income and middleincome countries. Lancet 2007;370:1164-74.

57. WHO. Smart governance for health and well-being: the evidence. Copenhagen: WHO Regional Office for Europe, 2014.

58. Adam T, de Savigny D. Systems thinking for strengthening health systems in LMICs: need for a paradigm shift. Health Policy Plan 2012;27 Suppl 4:iv1-iv3.

59. Atun R, Menabde N. Health systems and systems thinking. In: Coker R, Atun R, Mckee M, eds. Health Systems and the Challenge of Communicable Diseases. Maidenhead:: Open University Press, 2008.

60. In: de Savigny D, Adam T, eds. Systems Thinking for Health Systems Strengthening. Geneva: World Health Organization, 2009.

61. In: Saltman RB, Bankauskaite V, Vrangbæk K, eds. Decentralization in Health Care. Maindehead: Open University Press, 2007.

62. Kringos DS, Boerma WG, Bourgueil Y, et al. The European primary care monitor: structure, process and outcome indicators. BMC Fam Pract 2010;11:81.

63. Donabedian A. Evaluating the Quality of Medical Care. Milbank Mem Fund Q 1966;44:166-203.

64. Smith J, Noble H. Bias in research. Evid Based Nurs 2014;17:100-1.

65. Chew-Graham CA, May CR, Perry MS. Qualitative research and the problem of judgement: lessons from interviewing fellow professionals. Fam Pract 2002;19:285-9.

66. Samb B, Desai N, Nishtar S, et al. Prevention and management of chronic disease: a litmus test for health-systems strengthening in low-income and middle-income countries. Lancet 2010;376:1785-97.

67. Schäfer W, Groenewegen PP, Hansen J, et al. Priorities for health services research in primary care. Qual Prim Care 2011;19:77-83.

68. De Maeseneer JM, De Sutter A. Why research in family medicine? A superfluous question. Ann Fam Med 2004;2 Suppl 2:S17-S22.

69. Ssenyonga R, Seremba E. Family medicine's role in health care systems in Sub-Saharan Africa: Uganda as an example. Fam Med 2007;39:623-6

70. Kringos DS. The importance of measuring and improving the strength of primary care in Europe: results of an international comparative study. Turkiye Aile Hekimligi Dergisi 2013;17:165-79.

71. Kieny MP, Bekedam H, Dovlo D, et al. Strengthening health systems for universal health coverage and sustainable development. Bull World Health Organ 2017;95:537-9. 